\title{
The trouble with human capital theory
}

Blair Fix [York University, Toronto, Canada]

\author{
Copyright: Blair Fix 2018 \\ You may post comments on this paper at \\ https://rwer.wordpress.com/comments-on-rwer-issue-no-86/
}

\begin{abstract}
Human capital theory is the dominant approach for understanding personal income distribution. According to this theory, individual income is the result of "human capital". The idea is that human capital makes people more productive, which leads to higher income. But is this really the case? This paper takes a critical look at human capital theory and its explanation of personal income distribution. I find that human capital theory's claims are dubious at best. In most cases, the theory is either not supported by evidence, is so vague that it is untestable, or is based on circular reasoning. In short, human capital theory is a barrier to the scientific study of income distribution. ${ }^{1}$
\end{abstract}

Keywords human capital theory, income distribution, critique, hierarchy, productivity, power

\section{Introduction}

Human capital theory is the dominant approach for understanding personal income distribution. According to this theory, individual income is the result of 'human capital'. The idea is that human capital makes people more productive, which leads to higher income. But is this really the case? This paper takes a critical look at human capital theory and its explanation of personal income distribution. I find that human capital theory's claims are dubious at best. In most cases, human capital theory is either not supported by evidence, is so vague that it is untestable, or is based on circular reasoning. In short, human capital theory is a barrier to the scientific understanding of income distribution.

Human capital theory's causal chain

$$
\text { human capital } \Longrightarrow \text { productivity } \Longrightarrow \text { income }
$$

My discussion is organized around human capital theory's causal chain, shown above. What I hope to show is that this causal chain is deeply flawed and is contradicted by the available evidence.

After a brief review of the origins of human capital theory (Section 2), I investigate the link between productivity and income (Section 3). Scores of empirical investigations have purported to find evidence for such a link. The problem is that they are all based on circular logic. They find a link between productivity and income because they measure productivity in terms of income. But when productivity is measured objectively using physical units, the link between income and productivity becomes tenuous. I find that productivity differences between workers are too small to explain observed levels of income inequality. A further problem is that productivity may not even be an "individual trait", as human capital theory claims. Evidence from animal studies suggest that social setting can affect individual productivity. In other words, productivity can be a 'social trait'.

\footnotetext{
${ }^{1}$ Data and analysis for this paper are available at the Open Science Framework: https://osf.io/m9gpc/
} 
After finding little evidence for the productivity-income hypothesis, I look for a relation between human capital and income (Section 4). I find that this leads to a Catch-22 situation. If we use an expansive definition of human capital, objective measurement becomes virtually impossible. But if we use a restrictive definition (that is measurable), we can account for only a small fraction of income variation. Proponents of human capital theory often use a bait switch technique. They begin with an expansive definition of human capital that is unmeasurable. But when it comes time to justify the theory, they point to the (very modest) empirical success of a narrow definition of human capital. The form of human capital that is most often trumpeted is education. The problem is that education's effect on income appears to be dwarfed by the effect of hierarchical rank.

In Section 5, I consider the possibility that hierarchical rank is just a potent form of human capital. But this hypothesis has a key deficiency. Hierarchical income gains are far larger than the observed differences in human productivity. But if not productivity, then what explains income returns to hierarchical rank? It is here that human capital theory becomes a barrier to scientific progress. When we assume that income is caused by characteristics of the individual, we fail to consider the obvious alternative. What if individual income has a social cause? In a hierarchy, the most obvious social cause is the chain of command, which is effectively a tool for concentrating power. What if power explains the returns to hierarchical rank? I find evidence to support this hypothesis. Relative income within firms scales strongly with the number of subordinates (which I take to be a measure of hierarchical power).

I conclude in Section 6 with thoughts about future directions for income distribution theory. If we abandon human capital theory, what should we replace it with? I think we should focus on the power relations within social hierarchy. Hopefully this will allow us to move forward from the half-century dead-end that has been human capital theory.

\section{Human capital theory's origins}

Human capital theory originated in the mid-20 $0^{\text {th }}$ century work of Mincer (1958), Schultz (1961), and Becker (1962). These authors proposed a remarkably simple explanation of personal income. The idea is that individuals can gain skills (human capital) that will make them more productive. This enhanced productivity then leads to greater income. As I discuss below, this was not a new idea. The main accomplishment of human capital theory was to make this vision consistent with the rest of neoclassical theory.

In many ways, human capital theory was an inevitable byproduct of a century of political economic thought. The key ingredient was the deep-rooted productivity-income hypothesis. The idea that income stems from productivity has been a central tenet of political economy for more than a century. It was formalized in neoclassical theory by Wicksteed (1894) and Clark (1899). Both authors theorized that income distribution obeyed a "natural law". In a market economy, each factor of production would earn its marginal product. This was the incremental increase in output caused by the incremental increase in input of capital/labor. Thus, if a capitalist earned more than a worker, it was because an additional unit of 'capital' added more to output than an additional unit of labor.

Marginal productivity theory was developed to explain functional income distribution - the income split between workers and capitalists. But it logically implies a theory of personal income distribution. Let's suppose that the productivity-income relation is universal. It follows 
that income differences between workers (who all earn labor income) must be due to differences in individual productivity. In hindsight, the development of human capital theory was only a matter of time. According to neoclassical theory, capitalist income stems from the productivity of capital. Maybe something similar is true for workers? This was the hypothesis proposed by Mincer, Schultz, and Becker. Suddenly we could think of "skills" as "human capital", just like we could think of machinery as "capital". Wage differences between workers could then be attributed to differences in "human capital".

Incidentally, neoclassical thinkers were not the only ones to arrive at this conclusion. Some Marxists had very similar ideas. On the face of it, Marxist theory is diametrically opposed to neoclassical theory. Marx (1867) thought that capitalists earned their income by exploiting workers. This was very different from the neoclassical vision of class harmony. But what about income differences between workers? Here, Marxist theory and human capital theory are not that far apart. According to Marx, labor produces all value. But this implies that highpaid skilled workers must be more productive than low-paid unskilled workers. What accounts for these productivity differences? According to the Soviet economist Isaak Illich Rubin (1973), it is the additional training of skilled workers that makes them more productive. This thinking is virtually identical to human capital theory.

Thus, the productivist tendencies of political economy naturally led to some form of human capital theory. But there is a major sticking point to this approach. If income is caused by productivity, then human productivity must be as unequally distributed as income (or nearly so). But this possibility was challenged by the work of Francis Galton and Vilfredo Pareto. Galton (1869) discovered that human characteristics were normally distributed. No matter what was measured (height, weight, IQ, etc.), human characteristics tended to clump around an average value. It follows that human productivity should also be normally distributed. The problem is that income bucks this trend. Vilfredo Pareto (1897) showed that income distributions were highly skewed. Income was far more unequally distributed than were human characteristics. Political economists have been grappling with this paradox for a century (Sahota, 1978).

The most common resolution to the Galton-Pareto paradox is to assume that abilities have a multiplicative effect on productivity (Boissevain, 1939; Mandelbrot, 1960). Human abilities remain normally distributed, thus satisfying Galton's findings. At the same time, the multiplicative effect means that productivity can be highly skewed. This satisfies Pareto's findings. This thinking is often expressed as a production function. Workers' output $(\mathrm{Y})$ is written as an exponential function of the sum of different abilities $\left(a_{\mathrm{i}}\right)$ :

$Y=e^{a_{1}+a_{2}+\ldots+a_{i}}$

This thinking begs a question. Are abilities innate? Or are they learned? Human capital theory asserts that most abilities are learned. But this has been a major source of controversy. According to 'screening' theory, education does not increase ability. Instead, education simply sorts individuals by their pre-existing abilities (Spence, 1978; Hungerford and Solon, 1987).

While historically important, I find this 'screening' debate largely irrelevant. The important question is not whether abilities are innate or acquired. Instead, the important question is can productivity differences explain income differences? If not, then both screening theory and human capital theory have a serious problem. 


\section{Productivity and income}

Any theory worth its salt must make falsifiable predictions. Human capital theory's prediction is unambiguous: workers' income stems from productivity. Unfortunately testing this prediction leads to a measurement quagmire from which few economists escape.

\subsection{A measurement quagmire}

To measure a worker's marginal productivity, we must isolate the change in a firm's output that is due to the change in labor input alone. In most situations, this is virtually impossible (Pullen, 2009). For instance, we must be able to objectively measure the quantity of capital, in order to hold it constant. But as the "Cambridge capital controversy" showed, we cannot measure the quantity of capital independently from the distribution of income (Cohen and Harcourt, 2003; Hodgson, 2005; Nitzan and Bichler, 2009; Robinson, 1953; Sraffa, 1960). Since it is the distribution of income that we wish to explain, this is a bit of a problem.

We must also be able to objectively measure output. But how do we compare workers who have qualitatively different outputs? For instance, how can we determine if a potato farmer is more productive than a composer? Neoclassical theory solves the problem by slight of hand. It assumes a one-commodity economy, in which output comparison problems do not exist (Colacchio, 2018).

But applied economists cannot be content with this approach. Real-world tests of marginal productivity theory require comparing workers with different outputs. This means choosing a common quantitative attribute of analysis. But the choice of attribute is subjective, and different attributes will lead to different results. Economists make things worse by choosing monetary value as the attribute of comparison. Thus, labor productivity is generally measured using sales or value-added per worker (Abowd et al., 1999; Haltiwanger et al., 1999; Haskel et al., 2005; Hellerstein et al., 1996; Hoegeland, 1999; Iranzo et al., 2008; Oulton, 1998). The problem with this approach is that it relies on circular logic. According to theory, income is explained by productivity. But when the theory is tested, productivity is defined in terms of income.

Based purely on accounting principles, we expect wages to be correlated with sales/valueadded per worker. Double entry accounting principles dictate that firm value added $(Y)$ is equivalent to the sum of all wages $(\mathrm{W})$ and capitalist income $(\mathrm{K})$. If we divide by the number of workers $(L)$, we find that value-added per worker is equivalent to the average wage $(w=W / L)$ plus K/L:

$\frac{Y}{L}=\frac{W+K}{L}=w+\frac{K}{L}$

Sales (S) are similar, but include an additional non-labor cost term (C):

$$
\frac{S}{L}=\frac{W+K+C}{L}=w+\frac{K+C}{L}
$$


Figure 1 Labor productivity inequality vs. income inequality

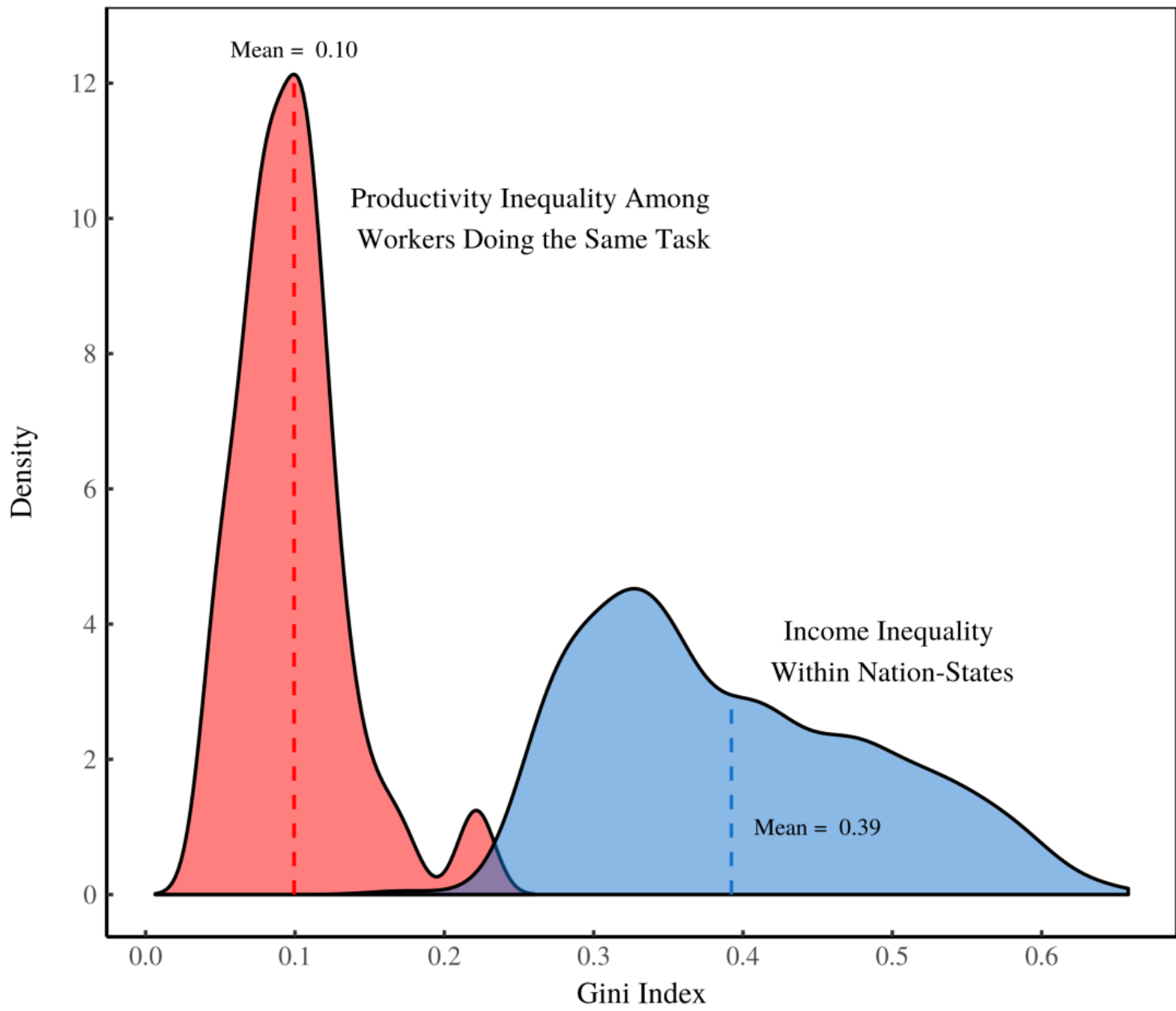

Note: Using a Gini index, this figure compares the inequality of worker productivity to income inequality within nation-states. Data for worker productivity dispersion comes from Hunter et al. (1990), who report the coefficient of variation of productivity among workers conducting the same task. Data plotted here shows the distribution of productivity inequality for 52 different tasks. I convert Hunter's data to a Gini index by assuming that worker productivity is lognormally distributed. The Gini index (G) of a lognormal distribution with a coefficient of variation $\mathrm{c}_{\mathrm{v}}$ is

$$
G=\left(\frac{1}{2} \sqrt{\log \left(c_{0}^{2}+1\right)}\right) \text {. }
$$

I plot the resulting distribution against the distribution of Gini indexes of income inequality for all countryyear observations in the World Bank database (series SI.POV.GINI).

Thus, if we look for a correlation between average wage $(\mathrm{w})$ and value-added/sales per worker (Y/L or $S / L)$, we will surely find it. Simple accounting definitions dictate that average wage is a major component of value-added per worker.

\subsection{Measuring productivity differences objectively}

Under what conditions can we objectively compare differences in workers' output? The conditions are extremely restrictive. We can only compare workers who produce the same output. Most economists have not been interested in such measurements. However, the psychologist John E. Hunter made it part of his life's work. Hunter et al. (1990) report output 
variability among workers doing the same task. Importantly, many different types of tasks are measured.

The question is, how great is this output variability? Can it conceivably account for observed levels of income inequality? I test this possibility in Figure 1. For each of the 52 different tasks measured by Hunter et al., I calculate a Gini index of productivity inequality. I then plot the spread of this labor productivity inequality. The results cluster around a Gini index of 0.1. Interestingly, this is consistent with the known dispersion of human abilities. For instance, we can take the SAT test as one measure of human ability. In 2017, the average score on the US SAT was 1060, and the standard deviation was 195 (CollegeBoard, 2017). Assuming a normal distribution, this corresponds to a distribution of ability with a Gini index of 0.1.

How does this productivity dispersion compare to levels of income inequality? To make this comparison, Figure 1 plots the distribution of income inequality within all nation-states in the World Bank database. The results do not bode well for human capital theory. Productivity inequality is far too small to account for observed levels of income inequality.

\subsection{Is productivity an "individual trait"?}

Let's be generous to human capital theory and put aside this under-explanation problem. Let's suppose that productivity inequality is similar to income inequality. Even then, there is a problem with the productivity-income hypothesis. Human capital theory assumes that productivity is an individual trait. But this could be wrong. Individual productivity could be a social trait.

Experiments by the poultry geneticist William Muir highlight this possibility. Muir conducted selective-breeding experiments that attempted to raise chickens' egg-laying productivity. In one experiment, Muir selected the most productive hen from each group to breed the next generation of hens. What happened? Evolutionary biologist David Sloan Wilson summarizes:

"Egg productivity plummeted, even though the best egg-layers had been selected each and every generation. The reason for this perverse outcome is easy to understand, at least in retrospect. The most productive hen in each cage was the biggest bully, who achieved her productivity by suppressing the productivity of the other hens" (Muir and Wilson, 2016, emphasis added).

The lesson, according to Wilson, is that traits that can be "measured at the individual level" may not actually be "individual traits":

"Muir's experiments ... challenge what it means for a trait to be regarded as an individual trait. If by 'individual trait' we mean a trait that can be measured in an individual, then egg productivity in hens qualifies. You just count the number of eggs that emerge from the hind end of a hen. If by 'individual trait' we mean the process that resulted in the trait, then egg productivity in hens does not qualify. Instead, it is a social trait that depends not only on the properties of the individual hen but also on the properties of the hen's social environment" (Muir and Wilson, 2016).

Human capital theory makes a seemingly self-evident assumption: the productivity of individuals is an "individual trait". But as Wilson notes, this is faulty logic. When we study 
productivity differences among humans, we must consider the social context. Just as with hens, highly productive humans may actually be suppressing the productivity of others. This behavior would invalidate the premise of human capital theory (and much of neoclassical economics).

\section{Human capital and income}

Human capital theory posits a joint relation between human capital, productivity, and income. Unfortunately, the productivity-income component seems tenuous at best. But perhaps there is still a link between income and human capital? Let's investigate.

The human-capital-income link has been a Catch-22 for empirical researchers. On the one hand, restrictive definitions of human capital correlate poorly with income. On the other hand, expansive definitions of human capital are often so vague that they are unmeasurable. The first problem was recognized by Jacob Mincer, a pioneer of human capital theory. In his initial work, Mincer defined human capital restrictively as the number of years of formal education (Mincer, 1958). But he later found that this accounted for a very small portion of income variability:

"Simple correlations between earnings and years of schooling are quite weak. Moreover, in multiple regressions when variables correlated with schooling are added, the regression coefficient of schooling is very small" (Mincer, 1974).

In the face of this failure, many researchers broadened their definition of human capital in an ad hoc manner. For just one example, take Gregory Mankiw's definition in his bestselling microeconomics textbook. He defines human capital expansively as "the accumulation of investments in people" (Mankiw, 2012). It is hard to see how this could possibly be measured objectively.

What has become common is a bait-and-switch technique. Economists begin with an expansive definition of human capital that is unmeasurable. But when it comes to justifying the theory, they point to the modest empirical success of a more restrictive definition of human capital. Mankiw is a case in point. After offering his expansive definition above, Mankiw switches to a more restrictive definition to offer empirical evidence. He writes:

"The most important type of human capital is education. ... Not surprisingly, workers with more human capital on average earn more than those with less human capital" (Mankiw, 2012).

Of course, Mankiw fails to mention that the correlation between education and earnings is low. Still, income gains due to education are invariably used to justify human capital theory. Why? 
Figure 2 Returns to education, age, and experience in the BGH firm
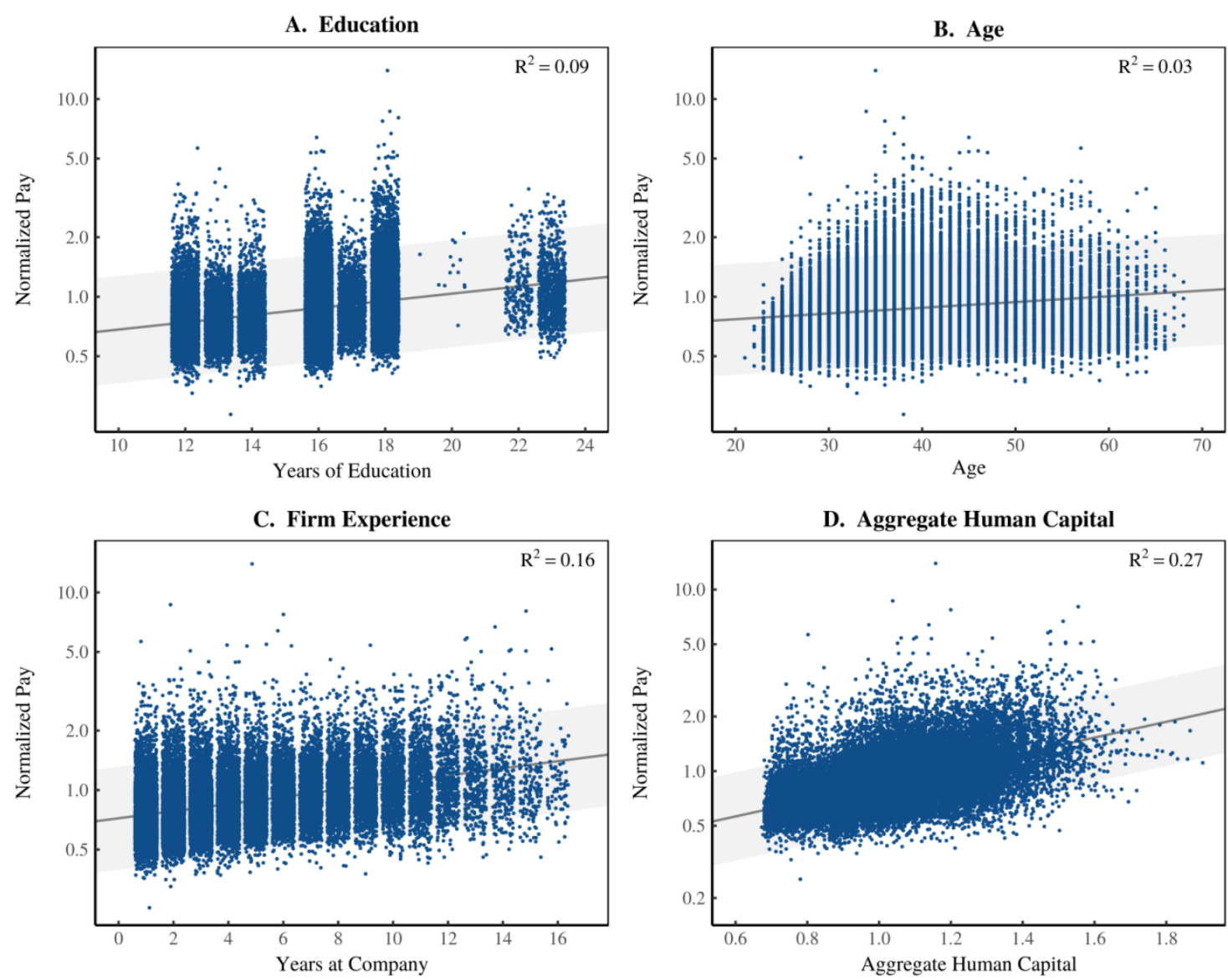

Note: This figure analyzes returns to education, age, and firm experience in the BGH firm from 1969 to 1985. The vertical axis of each panel shows normalized pay (income relative to firm average pay in the year in question). Each data point represents an individual in a given year. Panel A shows income returns to years of formal education. Panel B shows income returns with age. Panel $C$ shows income returns with years of firm experience. Panel $D$ shows the relation between income and individuals' aggregate human capital stock (see Equation 4). All $R^{2}$ values are from regressions on the logarithm of income. Grey regions indicate the $95 \%$ prediction interval for each regression. To better visualize discrete data, "jitter" has been added to the horizontal axis of Panels A-C.

\subsection{Education: the only game in town?}

It is true that education has a weak effect on income. But it is also true that almost everything we can measure about individuals has a weak effect on income (when measured by raw correlation). What is important is the relative size of an effect. In relative terms, the incomeeffect of education and training is quite strong. This is a fact that heterodox economists often begrudgingly concede to human capital theory (even if they do not accept human capital theory's explanation for the returns to education). In this sense, education is treated as the only game in town.

But is this actually the case? Does education (and other forms of training) affect income more strongly than any other factor? Cracks in this argument were first exposed by Eric Wright (1979). Wright found that hierarchical rank within firms affected income more than education. 
But how general is this result? Because the empirical work on firm hierarchy is quite sparse, it is difficult to say. However, the available case-study evidence does not bode well for human capital theory.

The most thorough case study of firm hierarchy (to date) was conducted by Baker, Gibbs and Holmstrom (1993). I will refer to this as the BGH study. BGH analyze the hierarchical structure of a large American firm for a period of two decades, beginning in the late 1960s. And unlike other case studies of firm hierarchy, BGH have made their raw data publicly available. I analyze the BGH dataset to see if Wright's results hold up.

Let's look first at the relation between individual income and years of formal education in the $\mathrm{BGH}$ firm. Figure 2A plots normalized income (income relative to the firm mean in a given year) against years of formal education. As expected there is a positive correlation, but it is weak. Next let's look at age. If we are generous to human capital theory, we can imagine age as measure of the human capital accumulated through life experience. As shown in Figure $2 \mathrm{~B}$, incomes increase with age, but the relation is very weak. What about firm experience? We can treat firm experience as a measure of on-the-job training and/or acquired skill. Not surprisingly, experience at the BGH firm has a significant effect on income (Fig. 2C).

Let's be generous to human capital theory and further suppose that education, age, and firm experience all contribute to an individual's aggregate stock of human capital, $\mathrm{K}$ :

$\mathrm{K}=c_{1}$ (education $)+c_{2}($ age $)+c_{2}($ firm experience $)$

How strongly does this aggregate human capital stock affect income? To answer this question, we need to provide values for the parameters $c_{1}, c_{2}$, and $c_{3}$. These parameters weight the various forms of human capital. To my knowledge, human capital theory provides no way of determining these parameters. Instead, econometricians typically estimate them using multivariate regression. This chooses parameters such that $K$ has the maximum effect on income.

Let's give human capital theory the benefit of the doubt and do this. I estimate Equation 4 parameters using a multivariate regression on the logarithm of income. I then see how strongly $\mathrm{K}$ predicts income. The results are shown in Figure 2D. As expected, the aggregate human capital stock $(K)$ affects income more strongly than education, age, or firm experience in isolation. Aggregate human capital accounts for roughly one third of the variation of log income in the BGH firm.

\subsection{Returns to hierarchical rank}

In the BGH firm, the income-effect of aggregate human capital is sizable. But the problem is that it pales in comparison to the effect of hierarchical rank. As shown in Figure 3, hierarchical rank accounts for almost two thirds of the variation of log income in the BGH firm. This is roughly double the income variation accounted for by our aggregate human capital stock.

But perhaps we are not being fair to human capital theory. It is possible that a large part of the returns to hierarchical rank are due to the returns to education, age, and firm experience. Conversely, it is possible that none of the returns to education, age, and firm experience are due to returns to hierarchical rank. We can untangle this relation using a multivariate analysis. 
I regress log income onto hierarchical rank, education, age, and firm experience. Table 1 shows the results. The table values represent the partial correlation between the given factor and log income. These values indicate the correlation when the effects of the other factors have been removed.

Again, the results do not sit well with human capital theory. The isolated effect of hierarchical rank is far larger than any human capital factor. Interestingly, the effect of firm experience disappears when we account for changes in hierarchical rank. This suggests that returns to firm experience are caused mostly by climbing the corporate ladder. In other words, individuals who fail to advance in rank do not have returns to firm experience.

Figure 3 Returns to hierarchical rank in the BGH firm

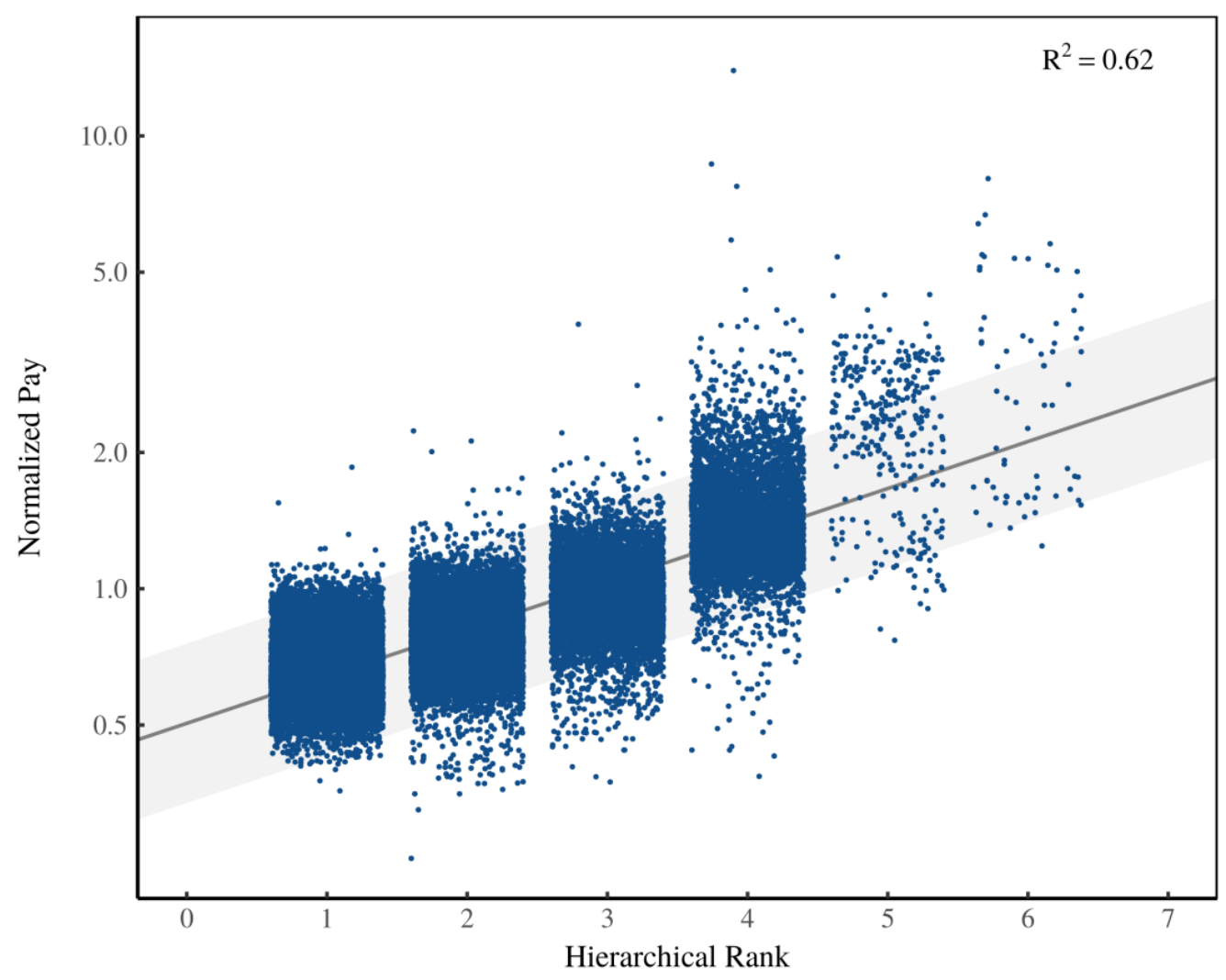

Note: This figure analyzes returns to hierarchical rank in the BGH firm from 1969 to 1985. The vertical axis of each panel shows normalized pay (income relative to firm average pay in the year in question). Each data point represents an individual in a given year. The $\mathrm{R}^{2}$ value is from a regression on the logarithm of income. The grey region indicates the $95 \%$ prediction interval of the regression. In order to better visualize discrete data, horizontal "jitter" has been added to the horizontal axis. 
Table $1 \mathrm{~A}$ Multivariate analysis of $\mathrm{BGH}$ data

\begin{tabular}{lc}
\hline & Partial Correlation with Log Income \\
\hline Hierarchical Rank & 0.705 \\
Education & 0.189 \\
Age & 0.103 \\
Firm Experience & -0.039 \\
\hline
\end{tabular}

Figure 4 Labor productivity inequality vs. income inequality between BGH hierarchical ranks

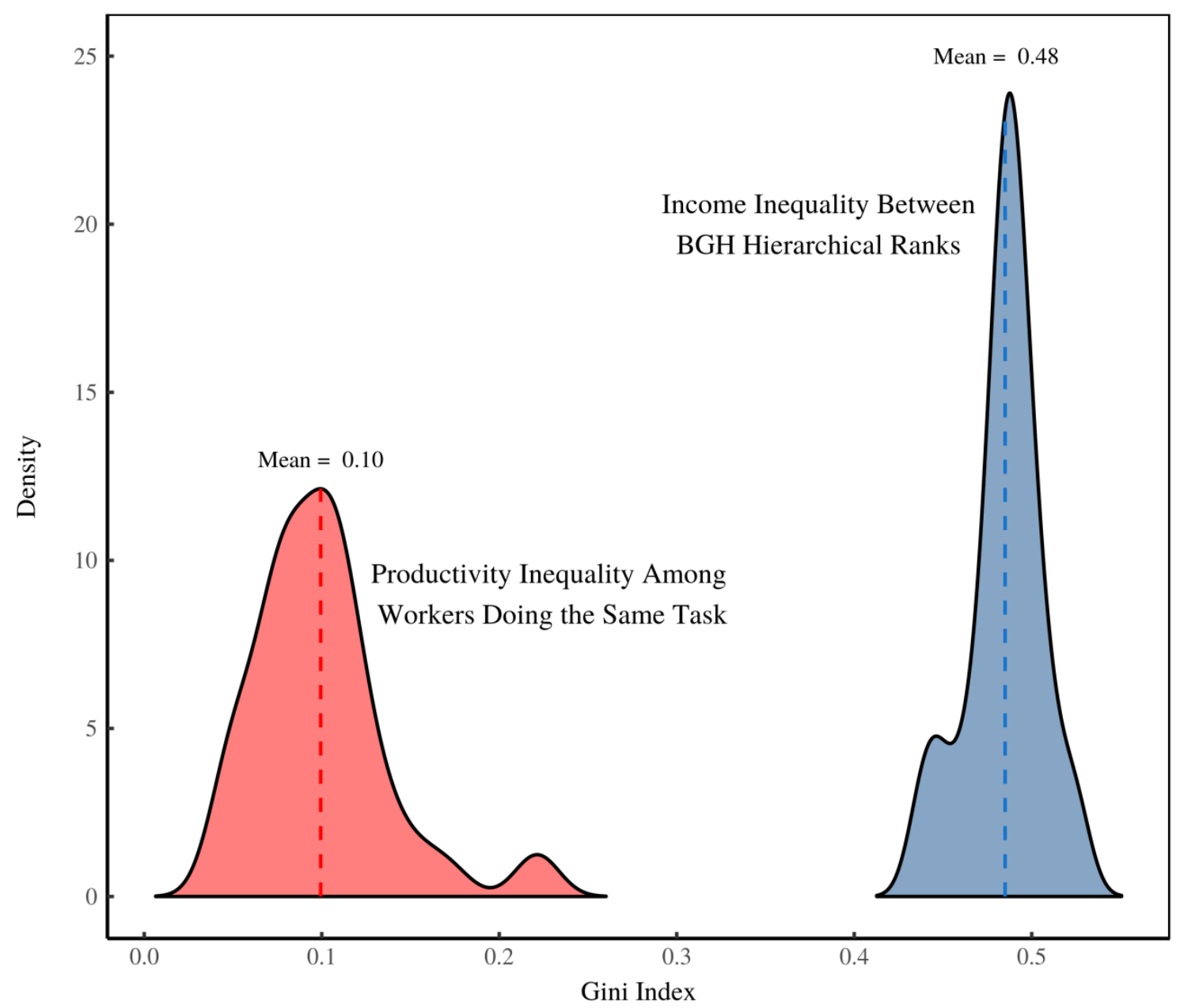

Note: Using a Gini index, this figure compares the inequality of task-specific worker productivity to income inequality between BGH hierarchical ranks. Data for worker productivity dispersion comes from Hunter et al. (1990). (For methods see Figure 1). Data plotted here shows the distribution of productivity inequality for 55 different tasks. I compare this to the income inequality between BGH hierarchical ranks. This equals the Gini index of hierarchical rank mean incomes. The blue density curve shows the distribution of annual observations. 


\section{Explaining income returns to hierarchical rank}

The BGH evidence suggests that hierarchical rank affects income far more than education (and other forms of training/experience). But perhaps this is not a blow to human capital theory. Maybe hierarchical rank indicates some unmeasured form of human capital? Let's consider this possibility.

The most general problem with this interpretation is that it has the hallmark of pseudoscience. Acemoglu and Autor (2011) call this the "unobserved heterogeneity issue". It is always possible to presume that "all pay differences are related to skills (even if these skills are unobserved to the economists in the standard data sets)" (ibid). While hinting that this is a problem, Acemoglu and Autor go on to state that it is "not a bad place to start when we want to impose a conceptual structure on empirical wage distributions" (ibid). I disagree. Karl Popper (1959) long ago cautioned against theories that can explain any conceivable evidence. To use Wolfgang Pauli's phrase, such theories are "not even wrong" (Burkeman, 2005).

But let's put aside this problem. If hierarchical rank is a form of human capital, what does this imply? Human capital theory is very clear that income is proportional to productivity. Thus, returns to hierarchical rank must indicate productivity difference between ranks.

But here we run into a problem. Income increases exponentially with hierarchical rank. Are these exponential returns really due to productivity gains? Unfortunately, we cannot test this directly, since we do not have direct (physical) measures of productivity for the BGH workers. What we can do is return to the task-specific productivity inequality shown in Figure 2. To reiterate, this is the productivity dispersion among workers doing the same task. I have argued that this is the only way to objectively measure individual productivity differences. Can this dispersion explain income inequality between BGH hierarchical ranks?

Figure 4 tests this possibility. Here I re-plot the productivity dispersion data from Figure 2. I then compare this to the income inequality between BGH hierarchical ranks. To get the latter, I calculate the mean income in each hierarchical rank of the firm (in a given year). I then calculate the Gini index of these mean incomes. This is equivalent to selecting a representative individual from each BGH hierarchical rank, and then measuring the income inequality between these individuals.

The results are unambiguous. Income inequality between $\mathrm{BGH}$ hierarchical ranks is far greater than our measure of productivity dispersion. Thus, it seems improbable that income returns to hierarchical rank are due to productivity gains. 
Figure 5 The exponential growth of hierarchical power with rank

Rank $=2$

Subordinates $=2$

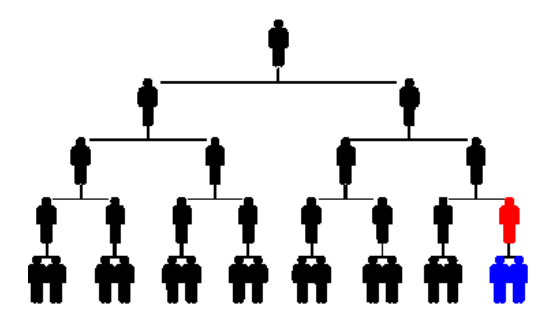

Rank $=3$

Subordinates $=6$

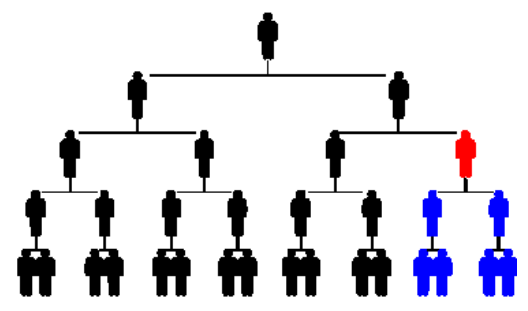

Rank $=4$

Subordinates $=14$

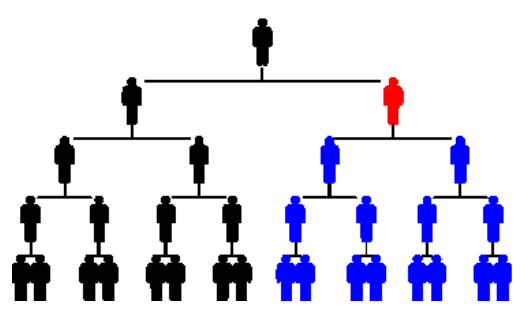

Rank $=5$

Subordinates $=\mathbf{3 0}$

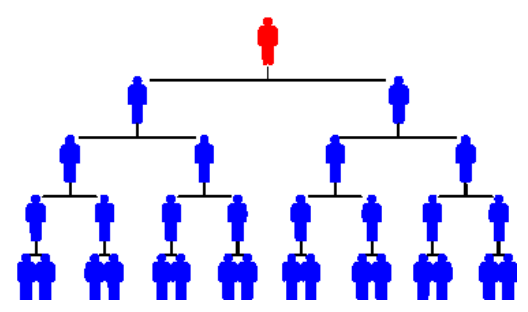

Note: In an idealized hierarchy, the total number of subordinates (blue) tends to grow exponentially with hierarchical rank (red).

\subsection{Power, not productivity}

If not productivity, then what explains the exponential returns to hierarchical rank? Here, human capital theory becomes a barrier to scientific progress. Why? The problem is that human capital theory puts the focus squarely on isolated individuals.

As long as we maintain this focus, we are blind to the obvious alternative hypothesis. What if income does not result from individual traits? What if income has a social cause?

Once we pose this alternative hypothesis, interesting ideas become possible. For instance, returns to hierarchical rank could be a function of power. This puts the focus on relations between people (not individual traits). One has power in relation to (and because of) others. Think of a military commander. His power is not an individual trait. Rather, it stems from other people's willingness to obey his commands. 
Figure 6 Average income vs. hierarchical power within case-study firms

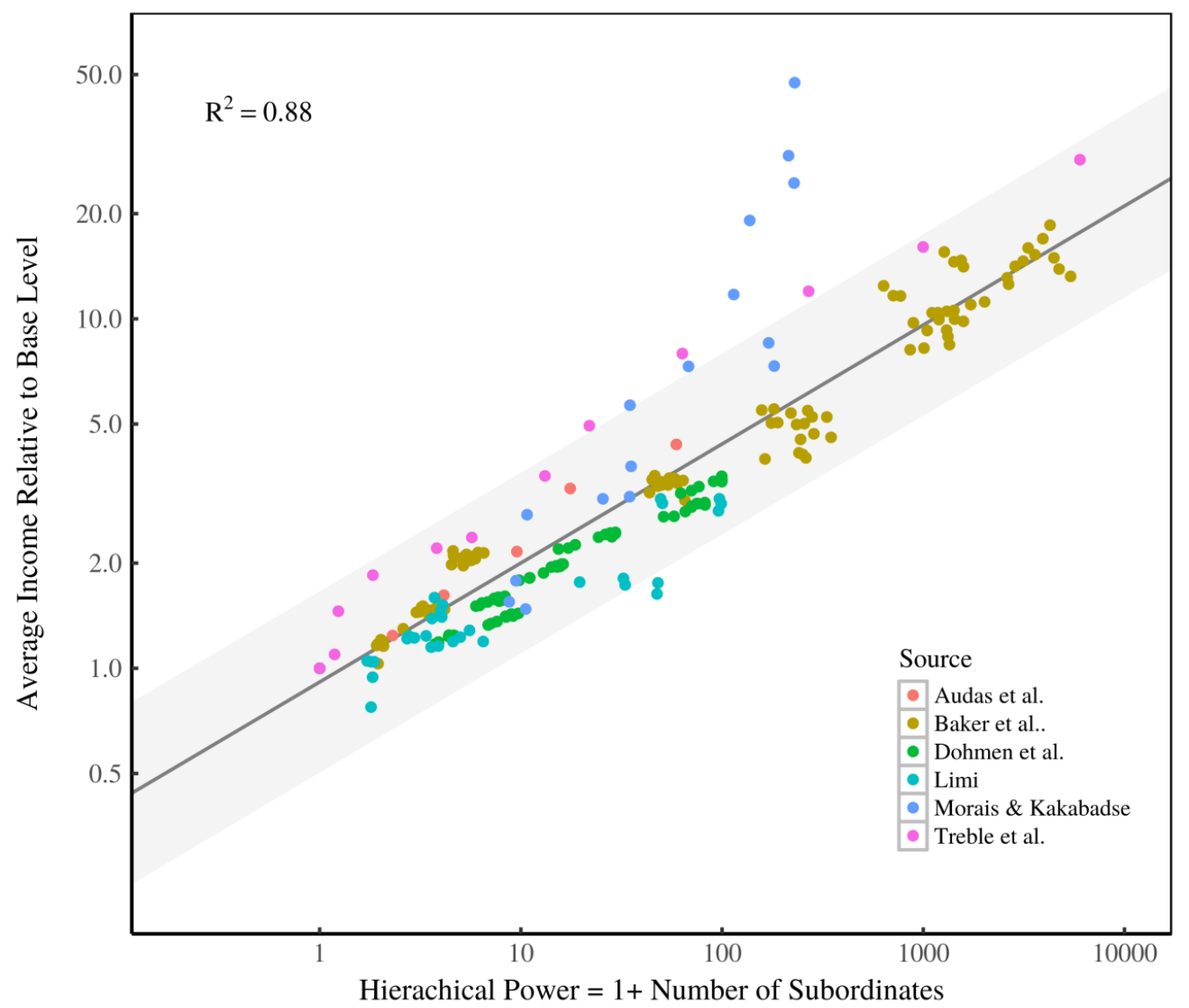

Note: This figure shows data from six firm case studies (Audas et al., 2004; Baker et al., 1993; Dohmen et al., 2004; Lima, 2000; Morais and Kakabadse, 2014; Treble et al., 2001). The vertical axis shows average income within each hierarchical level of the firm (relative to the base level), while the horizontal axis shows my metric for average power, which is equal to one plus the average number of subordinates below a given hierarchical level. Each point represents a single firm-year observation, and color indicates the particular case study. Grey regions around the regression indicate the 95\% prediction interval. See Fix (2018c) for a detailed discussion of sources and methods.

The general study of power is complex, since power can have many forms. But in a hierarchy, power is easier to pin down. A hierarchy is a nested set of power relations between superiors and subordinates. Each superior wields power over his direct subordinates, but also his indirect subordinates. This feature has important consequences. As illustrated by Figure 5, the total number of subordinates tends to grow exponentially with hierarchical rank.

But what does this have to do with power? Consider the following Weberian definitions of power:

1. "the possibility of imposing one's will upon the behavior of other persons" (Bendix 1998; cited in Wallimann et al. 1977)

2. "the chance of obtaining the obedience of others to a particular command" (Aron 1964; cited in Wallimann et al. 1977) 
These definitions suggest that power within a hierarchy should be proportional to the number of subordinates under one's control. I put this into formula form as:

\section{hierarchical power $=1+$ number of subordinates}

Everyone starts with a power of 1 , meaning they have control over themselves. Hierarchical power then increases linearly with the number of subordinates.

The question is, can hierarchical power explain the income returns to hierarchical rank? Figure 6 suggests that it can. Here I plot data from six case studies of firm hierarchy. The vertical axis indicates average income within each hierarchical rank (of each firm). The horizontal axis indicates the average hierarchical power of the rank in question. The result is a tight correlation. This suggests that income within these firms is mostly a function of social position, rather than individual traits.

The results in Figure 6 beg more questions. Why does this correlation exist? What is the mechanism at work? Is it social norms? Rules of thumb? Ideology? Is the correlation unique to these firms? Or universal across all firms? Does it change with time? These are all open questions. The important point is that these questions will not be posed if we remain fixated on human capital theory.

\section{Conclusions}

Science is reductionism. However, income distribution theory has tended towards greedy reductionism - a term coined by Daniel Dennet. He writes:

"in their eagerness for a bargain, in their zeal to explain too much too fast, [greedy reductionists] ... underestimate the complexities, trying to skip whole layers or levels of theory in their rush to fasten everything securely and neatly to the foundation" (Dennett, 1995).

Human capital theory is greedy reductionist. It offers extremely simple principles that purport to explain everyone's wages, all the time. It posits a universal connection between human capital, productivity, and income. But when we look closely at this causal chain, it breaks down entirely. For the most part, productivity differences between individuals cannot be measured objectively. Studies that claim to find a link between income and productivity do so by using circular logic. And when we restrict ourselves to the objective measurement of productivity, we find that individual productivity differences are systematically too small to account for levels of income inequality.

Furthermore, there is no agreed upon definition of human capital. Most definitions are so vague that they are unmeasurable. And when we define human capital restrictively, it can account for only a small portion of income variation. The primary empirical justification for human capital theory has always been the income returns to education. Yet the available evidence suggests that education returns are dwarfed by returns to hierarchical rank. And returns to hierarchical rank are so large that they cannot plausibly be explained in terms of productivity. 
To summarize, the evidence against human capital theory seems damning. And yet human capital theory continues to be the dominant theory of personal income distribution. Why? The problem is that economists treat human capital theory as though it were true by default. Neoclassical economists' unspoken article of faith is that wages stem from individual traits. All evidence is then interpreted as though this were true. If education and on-the-job training poorly explain income, this is not a problem. There must be some other skill that we are not measuring. Or what if hierarchical rank explains income better than education? Not a problem. Hierarchical rank must measure some form of human capital. When we think this way, the truth of human capital theory becomes a self-fulfilling prophecy.

We should not mince words. Human capital theory is a thought virus that is blocking the scientific study of income distribution. Alternative hypotheses are needed badly. I believe the most promising way forward is to focus on social hierarchy. When we do so, we acknowledge that individual income can have a social cause. The beauty of hierarchy is that it is both ubiquitous and it is simple enough that we can easily model it. The first step is to study how hierarchical rank affects income. This is difficult because the available data is sparse. But by using models, we can make estimates. For instance, using an empirically informed model, I have found that hierarchical rank affects US income more than any other factor for which data is available (Fix, 2018c). I have also found that firm hierarchy may be responsible for generating the power-law tail of US income distribution (Fix, 2018b). Hierarchy may even play a role in functional income distribution (Fix, 2018a).

These results are promising, but we should admit our state of ignorance. At present, we know very little about the role that hierarchy plays in determining income. And we will continue to know very little as long as human capital theory dominates the study of income distribution.

\section{References}

Abowd, John M., Francis Kramarz and David N. Margolis. 1999. "High wage workers and high wage firms." Econometrica 67 (2): 251-333.

Acemoglu, Daron and David Autor. 2011. Lectures in labor economics. Manuscript. http://economics. mit.edu/files/468922.

Aron, Raymond. 1964. German sociology. New York: Free Press.

Audas, Rick, Tim Barmby and John Treble. 2004. "Luck, effort, and reward in an organizational hierarchy.” Journal of Labor Economics 22 (2): 379-395.

Baker, George, Michael Gibbs and Bengt Holmstrom. 1993. "Hierarchies and compensation: A case study." European Economic Review 37 (2-3): 366-378.

Becker, Gary S. 1962. "Investment in human capital: A theoretical analysis." Journal of Political Economy 70 (5, Part 2): 9-49.

Bendix, Reinhard. 1998. Max Weber: an intellectual portrait, volume 2. Psychology Press.

Boissevain, C. Harry. 1939. "Distribution of abilities depending upon two or more independent factors." Metron 13 (4): pp. 49-58.

Burkeman, Oliver. 2005. "Briefing: Not even wrong." The Guardian (Sept. 19, 2005).

Clark, John Bates. 1899. The Distribution of Wealth. New York: Macmillan.

Cohen, Avi J. and Geoffrey C. Harcourt. 2003. "Retrospectives: Whatever happened to the Cambridge capital theory controversies?" Journal of Economic Perspectives 17 (1): 199-214. 
Colacchio, Giorgio. 2018. Marginal Product of Labor.

CollegeBoard. 2017. SAT Suite of Assessments Annual Report.

Dennett, Daniel C. 1995. Darwin's Dangerous Idea: Evolution and the Meanings of Life. London: Penguin Books.

Dohmen, Thomas J., Ben Kriechel and Gerard A. Pfann. 2004. "Monkey bars and ladders: The importance of lateral and vertical job mobility in internal labor market careers." Journal of Population Economics 17 (2): 193-228.

Fix, Blair. 2018a. "Capitalist Income and Hierarchical Power: A Gradient Hypothesis." SocArXiv. DOI 10.31235/osf.io/u8epv

Fix, Blair. 2018b. "Hierarchy and the Power-Law Income Distribution Tail." Journal of Computational Social Science 1 (2):471-491.

Fix, Blair. 2018c." Personal Income and Hierarchical Power." Journal of Economic Issues (in press) Preprint DOI: 10.31235/osf.io/pb475

Galton, Francis. 1869. Hereditary genius: An inquiry into its laws and consequences, volume 27. Macmillan.

Haltiwanger, John C., Julia I. Lane and James R. Spletzer. 1999. "Productivity differences across employers: The roles of employer size, age, and human capital." American Economic Review 89 (2): 94-98.

Haskel, Jonathan, Denise D. Hawkes and Sonia C. Pereira. 2005. "Skills, human capital and the plant productivity gap: UK evidence from matched plant, worker and workforce data." CEPR Discussion Paper (5334).

Hellerstein, Judith K., David Neumark and Kenneth R. Troske. 1996. "Wages, productivity, and worker characteristics: Evidence from plant-level production functions and wage equations." Technical Report Working Paper No. 5626, National Bureau of Economic Research.

Hodgson, Geoffrey M. 2005. "The fate of the Cambridge capital controversy." In Capital controversy, post Keynesian economics and the history of economic thought, pp. 112-125, Routledge.

Hoegeland, T. 1999. "Do higher wages reflect higher productivity? Education, gender and experience premiums in a matched plant-worker data set." Contributions to Economic Analysis 241: 231-260.

Hungerford, Thomas and Gary Solon. 1987. "Sheepskin effects in the returns to education." The review of economics and statistics 69 (1): 175-177.

Hunter, John E., Frank L. Schmidt and Michael K. Judiesch. 1990. "Individual differences in output variability as a function of job complexity.” Journal of Applied Psychology 75 (1): 28.

Iranzo, Susana, Fabiano Schivardi and Elisa Tosetti. 2008. "Skill Dispersion and Firm Productivity: An Analysis with Employer-Employee Matched Data." Journal of Labor Economics 26 (2): 247-285.

Lima, Francisco. 2000. "Internal Labor Markets: A Case Study." FEUNL Working Paper 378.

Mandelbrot, Benoit. 1960. "The Pareto-Levy law and the distribution of income." International Economic Review 1 (2): 79-106.

Mankiw, N. Gregory. 2012. Principles of microeconomics. Mason, OH: South-Western, Cengage Learning, 6th edition.

Marx, K. 1867. Capital, Volume I. Harmondsworth: Penguin/New Left Review.

Mincer, Jacob. 1958. "Investment in human capital and personal income distribution." Journal of Political Economy 66 (4): 281-302.

Mincer, Jacob. 1974. "Progress in Human Capital Analysis of the Distribution of Earnings." Working Paper No. 53, National Bureau of Economic Research Cambridge, Mass., USA. 
Morais, Filipe and Nada K. Kakabadse. 2014. "The Corporate Gini Index (CGI) determinants and advantages: Lessons from a multinational retail company case study." International Journal of Disclosure and Governance 11 (4): 380-397.

Muir, William M. and David Sloan Wilson. 2016. "When the Strong Outbreed the Weak: An Interview with William Muir." The Evolution Institute. https://evolution-institute.org/when-the-strong-outbreed-theweak-an-interview-with-william-muir/

Nitzan, J. and S. Bichler. 2009. Capital as Power: A Study of Order and Creorder. New York: Routledge.

Oulton, Nicholas. 1998. "Competition and the dispersion of labour productivity amongst UK companies." Oxford Economic Papers 50 (1): 23-38.

Pareto, Vilfredo. 1897. Cours d'economie politique, volume 1. Librairie Droz.

Popper, Karl. 1959. The Logic of Scientific Discovery. New York: Hutchinson \& Co.

Pullen, John. 2009. The marginal productivity theory of distribution: a critical history. London: Routledge.

Robinson, Joan. 1953. "The production function and the theory of capital." Review of Economic Studies $21(2): 81-106$.

Rubin, Isaak Ilich. 1973. Essays on Marx’s theory of value. Black Rose Books Ltd.

Sahota, Gian Singh. 1978. "Theories of personal income distribution: a survey." Journal of Economic Literature 16 (1): 1-55.

Schultz, Theodore W. 1961. "Investment in human capital." American Economic Review 51 (1): 1-17.

Spence, Michael. 1978. “Job market signaling." In Uncertainty in Economics, pp. 281-306, Elsevier.

Sraffa, Perio. 1960. Production of commodities by means of commodities: Prelude to a critique of economic theory. London: Cambridge University Press.

Treble, John, Edwin Van Gameren, Sarah Bridges and Tim Barmby. 2001. "The internal economics of the firm: further evidence from personnel data." Labour Economics 8 (5): 531-552.

Wallimann, Isidor, Nicholas Ch Tatsis and George V. Zito. 1977. "On Max Weber's definition of power." Australian and New Zealand Journal of Sociology 13 (3): 231-235.

Wicksteed, Philip H. 1894. An Essay on the Co-ordination of the Laws of Distribution (1932 Edition). London: London School of Economics.

Wright, Erik Olin. 1979. Class structure and income determination, volume 2. New York: Academic Press.

Author contact: blairfix@gmail.com

SUGGESTED CITATION:

Blair Fix, "The trouble with human capital theory", real-world economics review, issue no. 86, 10 December 2018, pp. 15-32, http://www.paecon.net/PAEReview/issue86/Fix86.pdf

You may post and read comments on this paper at https://rwer.wordpress.com/comments-on-rwer-issue-no-86/ 